\title{
ETV6-NTRK3 is Associated With Trisomy 8 and Sensitive to TRK Inhibitor in Hematologic Malignancy: Case Report of a Refractory AML and Review of the Literature
}

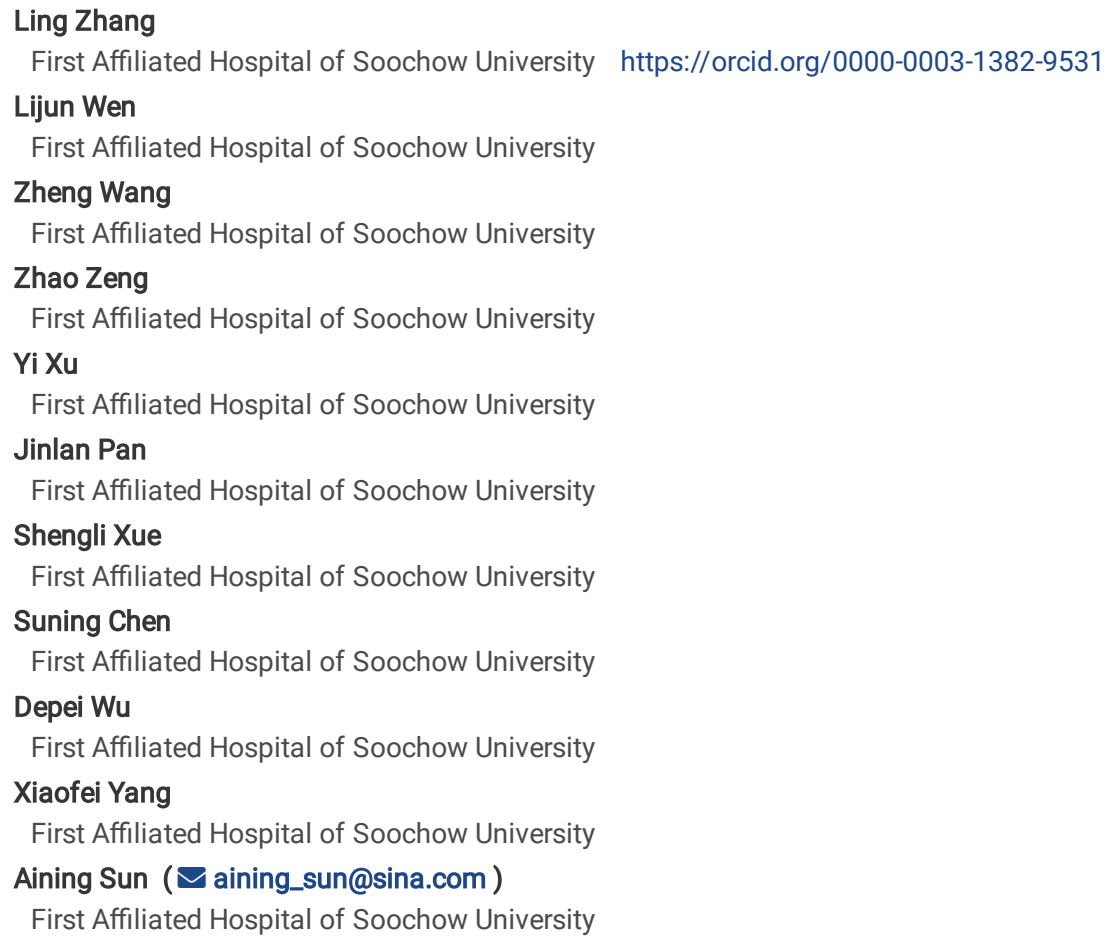




\section{Abstract}

Background: The ETV6-NTRK3 fusion transcript has been found to recurrently identified in both solid tumors and leukemias. It has attracted a lot of interest for the clinical targeted therapy and genetic features in ETV6-NTRK3 positive solid tumors. While the t(12;15)(p13;q25)/ETV6-NTRK3 is a rare genetic aberration in hematologic malignancies at a low frequency of $\leq 1 \%$. An accumulation of reported cases would be needed to discuss clinical and cytogenetic characteristics of the important entity. Therefore, it is useful to report every case for clinical implication of prognosis or therapy.

Case presentation: We report the case of a previously healthy 30-year-old female, who was diagnosed as acute myeloid leukemia (AML) and presented with chemoresistance and short survival. The patient was treated with four cycles of chemotherapy but failed to achieve remission. Then the patient underwent a salvage haploidentical stem cell transplantation. Unfortunately, she worsened within 1 month and died of the refractory leukemia 35 days after transplantation. ETV6-NTRK3 rearrangement was revealed by RNA sequencing but the chromosomal translocation $\mathrm{t}(12 ; 15)(\mathrm{p} 13 ; \mathrm{q} 25)$ was cryptic by conventional karyotype analysis. We review the literature and find that the ETV6-NTRK3 fusion transcript is associated with cryptic karyotype, trisomy 8, aggressive and poor prognosis in hematologic malignancy. The clinical and laboratory characteristics of ETV6-NTRK3 positive hematologic malignancies are different from those of solid tumors. Nevertheless, tropomyosin receptor kinase (TRK) inhibitor has powerful anti-tumor activity in patients with TRK fusion-driven cancers, regardless of the tumor type.

Conclusions: We demonstrated that TRK inhibitor larotrectinib is an effective treatment on the primary bone marrow (BM) cells derived from the patient described here with ETV6-NTRK3 positive AML. Our report stresses the importance of screening for ETV6-NTRK3 fusion transcript in newly diagnosed leukemias and clinical treatment of TRK inhibitor in hematologic malignancies.

\section{Introduction}

Acute myeloid leukemia (AML) is a common hematologic malignancy that has highly cytogenetic and molecular heterogeneity.(1, 2) Chromosomal translocations resulting in the generation of fusion genes can be frequently found in AML, constituting the molecular basis of tumor formation and progression, and were referred to divide AML into several special subgroups(3), which in some term informed clinicians of biological and clinical characteristics and prognosis. The chromosomal translocation $\mathrm{t}(12 ; 15)(\mathrm{p} 13 ; \mathrm{q} 25)$, through which the N-terminal helix-loop-helix (HLH) dimerization domain of ETV6 fuses to the C-terminal protein tyrosine kinase (PTK) domain of NTRK3, has been implicated in both solid tumors and leukemias.(4-10) Oligomerization of the ETV6 HLH domain and activation of NTRK3 PTK domain, which leads to constitutive stimulation of Ras-Erk1/2, PI3K-Akt, and IGF1R signaling pathways $(10,11)$, are essential for ETV6-NTRK3-induced cellular transformation. $(12,13)$ Transduction of murine BM cells with ETV6-NTRK3expressing retroviruses followed by transplantation results in a rapid and fatal myeloproliferative disease resembling AML.(14) Limited cases of hematological malignancy were described in this important entity and additional cases are needed to delineate the characteristics of this rare entity.(15) We here present the characteristics and outcome of a patient with cryptic $t(12 ; 15)$ from the First Affiliated Hospital of Soochow University and other patients from a comprehensive literature search.

\section{Case Presentation}

We identified 14 cases with ETV6-NTRK3 fusion genes from the literature (Table 1), including 5 patients with AML, 1 patient with chronic eosinophilic leukemia (CEL), 1 patient with AML transformed from myelodysplastic syndromes (MDS), and the other 7 patients with B-cell acute lymphoblastic leukemias (B-ALL). The majority were males $(62.3 \%, 9 / 14)$. There is a remarkable male predominance in B-ALL patients $(85.7 \%, 6 / 7)$, and most cases were children or adolescents and young adults (AYA). Patients diagnosed as AML were older (range 45 to 69 -year-old). Data on cytogenetic analysis were available in 9 of the 14 patients; all of the nine patients had a cryptic $\mathrm{t}(12 ; 15)$ abnormality; six patients had complex karyotype; five patients had trisomy 8 ; two patients with AMLM0 and CEL, respectively, had monosomy 7; three patients diagnosed as B-ALL had trisomy 21 and two of them had del (17p), both of which were not found in AML or CEL. Relatively complete data were described in 7 of the 14 patients; three patients with AML were reported refractory and died of disease progression in a short time without remissions. The AP-1060 cell line derived patient and two patients with B-ALL suffered from frequent relapse and refractory(R/R), but the two R/R B-ALL were sensitive to TRK inhibitor, larotrectinib and remained long-term remission. The patient diagnosed as CEL failed to response to symptomatic treatment with prednisone and hydroxyurea. 
Table 1

ETV6-NTRK3 is associated with trisomy 8 in hematologic malignancy.

\begin{tabular}{|c|c|c|c|c|c|c|c|c|}
\hline Case & Age & Sex & Diagnosis & Karyotype & Therapy & $\begin{array}{l}\text { Clinical } \\
\text { outcome }\end{array}$ & $\begin{array}{l}\text { Breakpoint } \\
\text { of ETV6 }\end{array}$ & Reference \\
\hline 1 & 59 & $\mathrm{~F}$ & AML-M2 & $\begin{array}{l}48, X X, \operatorname{add}(6)(q 27),+8, \operatorname{inv}(12)(p 13 q 15) \\
\operatorname{add}(15)(q 25),+\operatorname{add}(15)(q 25)\end{array}$ & Chemotherapy & $\begin{array}{l}\text { Refractory, } \\
\text { died at } 4 \\
\text { months. }\end{array}$ & Exon4 & 5,29 \\
\hline 2 & ND & ND & AML-M0 & trisomy $13^{\star}$ & ND & ND & Exon4 & 20,45 \\
\hline 3 & 69 & M & $\begin{array}{l}\text { MDS- } \\
\text { AML }\end{array}$ & $\begin{array}{l}\text { 47,XY,add(4)(p16),add(7)(q35),+8,add(12) } \\
(\mathrm{p} 13), \operatorname{add}(18)(\mathrm{p} 11)[10]\end{array}$ & Chemotherapy & $\begin{array}{l}\text { Progression to } \\
\text { AML five } \\
\text { months after } \\
\text { diagnosis of } \\
\text { MDS-RAEB } \\
\text { and resistant } \\
\text { to } \\
\text { chemotherapy, } \\
\text { refractory, died } \\
\text { at } 2 \text { months } \\
\text { after } \\
\text { transformation } \\
\text { to AML. }\end{array}$ & Exon4 & 27 \\
\hline 4 & 55 & M & AML-M0 & Monosomy7,t(10;12)(q24;p13) & Chemotherapy & $\begin{array}{l}\text { Refractory, a } \\
\text { short period. }\end{array}$ & Exon5 & 8 \\
\hline 5 & 45 & M & AML-M3 & $\begin{array}{l}46, \mathrm{XY}, \mathrm{t}(3 ; 14)(\mathrm{p} 21 ; \mathrm{q} 11.2), \operatorname{add}(5)(\mathrm{q} 33), \operatorname{del}(6) \\
(\mathrm{q} 25), \operatorname{add}(12)(\mathrm{p} 13), \mathrm{t}(15 ; 17)(\mathrm{q} 22 ; \mathrm{q} 21)\end{array}$ & $\begin{array}{l}\text { ATRA + ATO } \\
\text { chemotherapy }\end{array}$ & $\begin{array}{l}\text { Forth relapse } \\
\text { at } 20 \text { months } \\
\text { later, } \\
\text { Refractory. }\end{array}$ & Exon4 & 21,30 \\
\hline 6 & 54 & $\mathrm{~F}$ & AML & ND & ND & ND & Exon4 & 22 \\
\hline 7 & 82 & $\mathrm{~F}$ & CEL & $46, X X,-7,+8$ & $\begin{array}{l}\text { Prednisone, } \\
\text { hydroxyurea }\end{array}$ & $\begin{array}{l}\text { Died at } 29 \\
\text { days after the } \\
\text { CEL diagnosis. }\end{array}$ & Exon5 & 23 \\
\hline 8 & adolescent & M & B-ALL & ND & $\begin{array}{l}\text { Crizotinib-PDX } \\
\text { model }\end{array}$ & $\begin{array}{l}\text { More sensitive } \\
\text { to crizotinib } \\
\text { than imatinib. }\end{array}$ & Exon5 & 18 \\
\hline 9 & 9 & M & B-ALL & $\begin{array}{l}\text { 49,Y,del(X)(q22q28),add(1)(p36.1),add(2) } \\
(\mathrm{q} 11.2), \mathrm{r}(3), \text { add (6)(p21), del(7)(q32q36),add } \\
(8)(\mathrm{q} 24), \operatorname{der}(12) \mathrm{t}(3 ; 12)(\mathrm{q} 21 ; \mathrm{q} 24), \operatorname{der}(13 ; 17) \\
\text { (q10;q10),add(15)(q24),del(16)(p11.2p13), } \\
\text { del(17) } \\
\text { (p11.2p13),+21,+21,+21,+21[14]/49,sl,add(22) } \\
\text { q11.2)[4]/46,XY[1]/49,sl,+del(X) } \\
\text { q22q28),+11,-21,-22[1] }\end{array}$ & ND & ND & Exon5 & 12 \\
\hline 10 & 26 & M & B-ALL & ND & ND & ND & Exon5 & 19 \\
\hline 11 & 6 & $M$ & B-ALL & $47, X Y,+15[19]$ & Larotrectinib & $\begin{array}{l}\text { CNS, high } \\
\text { MRD, relapsed } \\
\text { at fifty days } \\
\text { post-HSCT } \\
\text { (ocular, CNS, } \\
\text { bone marrow), } \\
\text { Larotrectinib } \\
\text { successful, in } \\
\text { remission. }\end{array}$ & ND & 26 \\
\hline 12 & 61 & M & B-ALL & $50, X Y,+8,+15, \operatorname{del}(17)(p 11.2),+21,+22$ & Larotrectinib & $\begin{array}{l}\text { Refractory, } \\
\text { crizotinib } \\
\text { failure. } \\
\text { Relapse, } \\
\text { Larotrectinib } \\
\text { successful, in } \\
\text { remission. }\end{array}$ & Exon4 & 24 \\
\hline 13 & 16 & M & B-ALL & $\begin{array}{l}93, X X Y Y,-3,+5,+5,+8,+8,-9,-15,-18,+21,-22 \\
{[17] / 46, X Y[3]}\end{array}$ & ND & ND & ND & 25 \\
\hline 14 & 11 & $\mathrm{~F}$ & B-ALL & ND & ND & ND & Exon5 & 22 \\
\hline 15 & 30 & $\mathrm{~F}$ & AML & $\begin{array}{l}49, X X, t(1 ; 12)(q 11 ; q 11), \operatorname{inv}(3)(p 21 q 26),+8,+ \\
12,+15,19 p+[10]\end{array}$ & Chemotherapy & $\begin{array}{l}\text { Refractory, } \\
\text { died at } 5 \\
\text { months. }\end{array}$ & Exon5 & $\begin{array}{l}\text { this } \\
\text { article }\end{array}$ \\
\hline
\end{tabular}


A 30-year-old female was admitted to our hospital in October 2019 for headache and anemia. The peripheral blood (PB) values were; white blood cells 11.55 $\times 10^{9} / \mathrm{L}$; hemoglobin $64 \mathrm{~g} / \mathrm{L}$, and platelets $56 \times 10^{9} / \mathrm{L}$. PB smear showed $23 \%$ circulating blasts, $5 \%$ promyelocytes, $1 \%$ myelocytes, $4 \%$ metamyelocytes, $19 \%$ neutrophils, $19 \%$ lymphocytes, $11 \%$ eosinophils, $15 \%$ monocytes, and $3 \%$ basophils. Clinical examination revealed splenomegaly but no signs of lymph nodes swelling and central nervous system leukemia. BM aspiration was failed due to dry tap and subsequent BM biopsy showed markedly hypercellular with $30 \%$ blasts and diffuse myelofibrosis (MF-3). (Fig. 1A) Immunophenotyping analysis of PB sample by flow cytometry showed a $24.7 \%$ blasts population positive for CD34, CD13, CD14, CD33, CD11b, and CD64. Cytogenetic analysis of the PB cells observed a karyotype of 49,XX,t(1;12)(q11;q11),inv(3) (p21q26),+8,+12,+15,19p+[10]. (Fig. 1B) Multiplex reverse transcription-polymerase chain reaction (RT-PCR) detected no common leukemia-related fusions. (Table S1) Next-generation sequencing identified somatic mutations in BCOR and ETV6. (Table S2-3) The clinical examinations of the patient were consistent with a diagnosis of AML, NOS according to the WHO classification.

She was treated with two cycles of idarubicin (IDA), combined with cytarabine (Ara-c) (IA regime) and two courses of chidamide, decitabine, IDA and low does Ara-C and granulocyte colony-stimulating factor (G-CSF) (DC-IAG regime). Unfortunately, no remission was achieved. Then the patient received an allogeneic PB stem cell transplantation from a healthy HLA-matched sibling donor after a modified busulfan and cyclophosphamide conditioning regimen. Cyclosporine and short course methotrexate were given as a graft-vs-host disease-prevention regimen. However, the condition of the patient worsened 15 days after transplantation and she died of refractory leukemia 35 days after transplantation. RNA-sequencing of the diagnostic PB sample was performed and revealed an ETV6-NTRK3 fusion with no reciprocal fusion detected. RT-PCR and subsequent sanger sequencing confirmed the ETV6-NTRK3 fusion. (Fig. 1C) The ETV6-NTRK3 fusion transcript involved HLH and entire central domain (exon 1 to exon 5) of ETV6 and PTK domain of NTRK3. The breakpoints were located in exon 5 of the ETV6 gene and exon 15 of the NTRK3 gene. (Fig. 1D)

Different studies have suggested that oncogenic TRK aberrations are amenable to targeted inhibition.(16, 17) Primary BM cells derived from our patient were cultured ex vivo and treated with serial concentration of larotrectinib for 8 and 16 hours, respectively. Immunoblotting examination of cell lysates showed that phosphorylation of TRK downstream signaling targets, STAT3, AKT and PLCY1, were inhibited in a dose-dependent manner. Larotrectinib induced cell death in a time and dose-dependent manner, which was observed by Caspase 3 activation and PARP cleavage. (Fig. 2C) We also evaluated the antiproliferative ability of larotrectinib, ponatinib and PKC412 against the patient-derived BM cells. Cell viability was measured following 48 -hour treatment with serial concentration of larotrectinib. The TRK fusion-driven primary BM cells was more sensitive to larotrectinib with the IC50 value of 3.151 nM in contrast with $18.55 \mathrm{nM}$ for ponatinib and $74.14 \mathrm{nM}$ for PKC412. (Fig. 2A) In addition, larotrectinib was much more potent against BM cells carrying TRK fusion than Kasumi-1 cell line ( $3.151 \mathrm{nM}$ versus $>1000 \mathrm{~nm}$ ) (Fig. 2B), which expressed the fusion protein AML 1-ETO.(18) Larotrectinib induces cell apoptosis, inhibits cell proliferation and TRK signaling in ETV6-NTRK3-rearrangement patient derived primary BM cells. These in vitro data support that larotrectinib is an effective treatment for TRK fusion-driven AML.

\section{Discussion And Conclusions}

ETV6-NTRK3 was a rare but recurrent molecular event in hematological malignancies.(19-22) Limited number of hematopoietic tumors have so far been reported, including $\operatorname{AML}(5,8,17,23,24), \operatorname{CEL}(25), \mathrm{B}-\mathrm{ALL}(12,17,21,22,26-28)$ and MDS transformed AML.(29, 30) The very aggressive clinical characteristics of this patient described here was similar to the firstly reported ETV6-NTRK3 positive patient diagnosed as AML-M2.(31) Both of the two patients (Case 1 and 15) were presented with splenomegaly and accompanied by severe fibrosis of the BM samples at the time of diagnosis, and died in a short period with no remissions achieved. The manifestation was also observed in the patient (Case 7) with a diagnosis of CEL and previous history of breast and pancreatic carcinomas. We speculate that this distinct manifestation might be associated with ETV6-NTRK3 fusion gene. The AML-M3 cell line AP-1060 was obtained from the patient (Case 5), who had relapsed for the fourth time resistant to all-trans retinoic acid and arsenic trioxide.(24, 32) The patient (Case 3) initially diagnosed as MDS aggressively progressed to AML and was died for persistent resistant to chemotherapy soon after the transformation.(29) In addition, four patients introduced in Case 1,3,4,15, respectively, were refractory to each treatment cycle with a short survival time, indicating primary drug resistance and poor outcome of the ETV6-NTRK3 fusion gene in AML. Furthermore, eosinophilia was described in Case 7 and 15, suggesting that ETV6NTRK3 fusion gene may be associated with myeloid neoplasms with eosinophilia. ETV6-NTRK3 positive B-ALL is associated with relapse and/or refractory diseases (Case 11 and 12). B-ALL harboring an ETV6-NTRK3 fusion gene accounts for approximately 1\% of the Philadelphia-like cases(21), and is characterized by rapid proliferation and infiltration of central nervous system in preclinical models.(27) However, ETV6-NTRK3 was relatively frequently detected in some rare non-hematologic malignancies/solid tumors, like congenital fibrosarcoma (CFS), congenital mesoblastic nephroma (CMN) and secretory breast carcinoma (SBC).(9) The presence of the ETV6-NTRK3 fusion gene indicate an excellent prognosis and highly sensitive to typical chemotherapy in some solid tumors as CFS and cellular CMN.(33)

There was a correlation between the expression of the ETV6-NTRK3 fusion gene and trisomy 11 in CMN as well as CFS, among which the polysomies of chromosomes 8 and 17 were also well known. $(6,34)$ We found a striking correlation between trisomy 8 and ETV6-NTRK3 fusion gene expression in hematological malignancies with available karyotypes (6/10 in total, 4/6 in AML/CEL and 2/4 in B-ALL, Table 1). Trisomy 8 is one of the most common numerical aberrations in AML, with an incidence between $10 \%$ and $15 \% .(20,35)$ Trisomy 8 is rarely observed in ALL. Notably, Valentina Nardi et al demonstrated that the patient (Case 12) relapsed due to an expansion of an ETV6-NTRK3 rearranged subclone that also carried trisomy 8, confirming the association described above. Furthermore, FISH analysis showed that $93.8 \%$ of the ETV6-NTRK3 positive SKK-1 cells, derived from the patient 3 , carried trisomy 8 , which was considered to gradually expand and have a growth advantage.(29) AML with trisomy 8 is classified as intermediate risk according to the European Leukemia Net (ELN) classification.(36) In the 11q23/MLL-rearranged AML, which implied an adverse prognosis, the addition of chromosome 8 seem to independently predicted a more favorable outcome.(37) However, CBFB/MYH11 rearrangement AML with trisomy 8 had an inferior OS.(38) Here, the co-occurrence of trisomy 8 does not change the adverse prognosis of the ETV6-NTRK3 fusion gene. 
However, trisomy 11 and 17 was absent in hematological malignancies, which was obviously different from non-hematological malignancies. We also found that ETV6-NTRK3 fusion gene was related to complex karyotype with a cryptic $\mathrm{t}(12 ; 15)(\mathrm{p} 13 ; \mathrm{q} 25)$ translocation, which has never been detected in hematological malignancies using a conventional technique. Nevertheless, the chromosome translocation could be detected in several cases of solid tumors. (39) Monosomy 7 was noted in myeloid leukemias harboring non-complex karyotype (Case 4 and 7, 2/2). Trisomy 21 and deletion 17p (containing the TP53 gene) were recurrent in ETV6-NTRK3 positive B-ALL (Case 9, 12 and 13,3/4 and 2/4 proportion respectively).

Various breakpoints of ETV6-NTRK3 have been identified. It was previously considered that exon 1 to exon 5 of the ETV6 were retained in the ETV6-NTRK3 fusion product of solid tumor, but leukemic fusion variant contained exon 1 to exon 4 , excluding exon 5 of the ETV6. $(8,23-25,40,41)$ We here found that the breakpoints of ETV6 were not specific to distinguish solid tumors from leukemias. The two variants of fusion transcripts identified in leukemias may function differently in cell transformation due to the entire central domain encoded by partly of exon 4 and the entire exon 5, enabling further protein-protein interactions. There are no differences in clinical outcome between the two fusion variants. The reciprocal NTRK3-ETV6 fusion gene was not detected in all reported leukemias but could be detected in solid tumors as CFS.(42)

All the patients treated with traditional chemotherapy had disease progression while on treatment or persistent chemo-resistant, clearly highlighting that leukemia with ETV6-NTRK3 fusion is not chemo-sensitive. These observations are in contrast with the excellent clinical response on the larotrectinib, a highly selective TRK inhibitor. It has shown robust and durable anti-tumor activity in solid tumors and also in two single cases of B-ALL related to relapse/refractory. $(4,26,28,43-46)$ It has been demonstrated that larotrectinib was effective on AML cell lines carrying TRK rearrangements (IMS-M2, M0-91) as well as primary BM cells of the patient reported here. $(27,47)$

In conclusion, we identified the ETV6-NTRK3 fusion gene in a patient with AML remaining refractory and surviving for a short term. Moreover, we present a study of this rare entity from a comprehensive literature search as a specific and important subgroup of hematological malignancies with poor outcome and usually an additional copy of chromosome 8 , which were different from solid tumors with good prognosis and always trisomy 11. Most importantly, the translocation $\mathrm{t}(12 ; 15)(\mathrm{p} 13 ; \mathrm{q} 25)$ is highly cryptic and easily overlooked in conventional cytogenetics. Newly diagnosed AML presented with myeloproliferative neoplasm clinal features such as splenomegaly, myelofibrosis, eosinophilia or trisomy 8 cytogenetic abnormality, may harbor ETV6-NTRK3 fusion transcript. Our study highlights the significance of combining multiple molecular techniques to early identify the cryptic t(12;15)(p13;q25)/ETV6-NTRK3 in hematological malignancies and also emphasizes the value of TRK inhibitors on patients with ETV6-NTRK3 positive hematological malignancies.

\section{Abbreviations}

AML: acute myeloid leukemia; TRK: tropomyosin receptor kinase; BM: bone marrow; HLH: helix-loop-helix; PTK: protein tyrosine kinase; CEL: chronic eosinophilic leukemia; MDS: myelodysplastic syndromes; B-ALL: B-cell acute lymphoblastic leukemias; AYA: adolescents and young adults; PB: peripheral blood; RT-PCR: reverse transcription-polymerase chain reaction; IDA: idarubicin; Ara-c: cytarabine; G-CSF: granulocyte colony-stimulating factor; CEL: chronic eosinophilic leukemia; CFS: congenital fibrosarcoma; CMN: congenital mesoblastic nephroma; SBC: secretory breast carcinoma; ELN: European Leukemia Net.

\section{Declarations}

\section{Ethical approval and consent to participate}

All procedures performed in studies involving human participants were in accordance with the ethical standards of the First Affiliated Hospital of Soochow University committee and with the 1964 Helsinki declaration and its later amendments or comparable ethical standards. Informed consent was obtained from all individual participants included in the study. This article does not contain any studies with animals performed by any of the authors.

\section{Consent for publication}

Written informed consent for research and publication from the patients was obtained.

\section{Availability of data and materials}

Data sharing is not applicable to this article as no datasets were generated or analysed during the current study.

\section{Competing interests}

The authors declare no competing financial interests.

\section{Funding}

This study was supported by grant from the National Key R\&D Program of China (2019YFA0111000), the National Natural Science Foundation of China (81700140, 81873449, 81970142, 81900130, 81970136, 82000132), the Natural Science Foundation of the Jiangsu Higher Education Institution of China (18KJA320005), the Natural Science Foundation of Jiangsu Province (BK20190180), China Postdoctoral Science Foundation (2018M632372), the priority academic program development of Jiangsu Higher Education Institution, Translational Research Grant of NCRCH (2020WSB11, 2020WSB13).

\section{Author contributions}


ANS designed this study. XFY and ANS wrote the manuscript; LZ, LJW and ZW analyzed RNA-seq data and performed research; ZZ and YX analyze the research data; JLP and SLX collected clinical data and samples; SNC and DPW gave advices for the study design and paper writing.

\section{Acknowledgements}

We thank all study participants, especially the patients and their families. We thank the staff of the Hematology Department of The First Affiliated Hospital of Soochow University, Jiangsu Institute of Hematology and Institute of Blood and Marrow Transplantation.

\section{References}

1. Cancer Genome Atlas Research N, Ley TJ, Miller C, Ding L, Raphael BJ, Mungall AJ, et al. Genomic and epigenomic landscapes of adult de novo acute myeloid leukemia. N Engl J Med. 2013;368(22):2059-74.

2. Dohner H, Weisdorf DJ, Bloomfield CD. Acute Myeloid Leukemia. N Engl J Med. 2015;373(12):1136-52.

3. Arber DA, Orazi A, Hasserjian R, Thiele J, Borowitz MJ, Le Beau MM, et al. The 2016 revision to the World Health Organization classification of myeloid neoplasms and acute leukemia. Blood. 2016;127(20):2391-405.

4. Amatu A, Sartore-Bianchi A, Siena S. NTRK gene fusions as novel targets of cancer therapy across multiple tumour types. ESMO Open. 2016;1(2):e000023.

5. Eguchi M, Eguchi-Ishimae M, Tojo A, Morishita K, Suzuki K, Sato Y, et al. Fusion of ETV6 to neurotrophin-3 receptor TRKC in acute myeloid leukemia with $\mathrm{t}(12 ; 15)(\mathrm{p} 13 ; \mathrm{q} 25)$. Blood. 1999;93(4):1355-63.

6. Knezevich SR, Garnett MJ, Pysher TJ, Beckwith JB, Grundy PE, Sorensen PH. ETV6-NTRK3 gene fusions and trisomy 11 establish a histogenetic link between mesoblastic nephroma and congenital fibrosarcoma. Cancer Res. 1998;58(22):5046-8.

7. Knezevich SR, McFadden DE, Tao W, Lim JF, Sorensen PH. A novel ETV6-NTRK3 gene fusion in congenital fibrosarcoma. Nat Genet. 1998;18(2):184-7.

8. Kralik JM, Kranewitter W, Boesmueller H, Marschon R, Tschurtschenthaler G, Rumpold H, et al. Characterization of a newly identified ETV6-NTRK3 fusion transcript in acute myeloid leukemia. Diagn Pathol. 2011;6:19.

9. Lannon CL, Sorensen PH. ETV6-NTRK3: a chimeric protein tyrosine kinase with transformation activity in multiple cell lineages. Semin Cancer Biol. 2005;15(3):215-23.

10. Tognon C, Garnett M, Kenward E, Kay R, Morrison K, Sorensen PH. The chimeric protein tyrosine kinase ETV6-NTRK3 requires both Ras-Erk1/2 and PI3kinase-Akt signaling for fibroblast transformation. Cancer Res. 2001;61(24):8909-16.

11. Tognon CE, Somasiri AM, Evdokimova VE, Trigo G, Uy EE, Melnyk N, et al. ETV6-NTRK3-mediated breast epithelial cell transformation is blocked by targeting the IGF1R signaling pathway. Cancer Res. 2011;71(3):1060-70.

12. Wang Y, Miller S, Roulston D, Bixby D, Shao L. Genome-Wide Single-Nucleotide Polymorphism Array Analysis Improves Prognostication of Acute Lymphoblastic Leukemia/Lymphoma. J Mol Diagn. 2016;18(4):595-603.

13. Cetinbas N, Huang-Hobbs H, Tognon C, Leprivier G, An J, McKinney S, et al. Mutation of the salt bridge-forming residues in the ETV6-SAM domain interface blocks ETV6-NTRK3-induced cellular transformation. J Biol Chem. 2013;288(39):27940-50.

14. Liu Q, Schwaller J, Kutok J, Cain D, Aster JC, Williams IR, et al. Signal transduction and transforming properties of the TEL-TRKC fusions associated with $t(12 ; 15)(p 13 ; q 25)$ in congenital fibrosarcoma and acute myelogenous leukemia. The EMBO journal. 2000;19(8):1827-38.

15. JL H. t(12;15)(p13;q25) ETV6/NTRK3 in Hematological malignancies. Atlas Genet Cytogenet Oncol Haematol. 2020;24(9):347-9.

16. Joshi SK, Davare MA, Druker BJ, Tognon CE. Revisiting NTRKs as an emerging oncogene in hematological malignancies. Leukemia. 2019;33(11):256374.

17. Taylor J, Pavlick D, Yoshimi A, Marcelus C, Chung SS, Hechtman JF, et al. Oncogenic TRK fusions are amenable to inhibition in hematologic malignancies. J Clin Invest. 2018;128(9):3819-25.

18. Asou H, Tashiro S, Hamamoto K, Otsuji A, Kita K, Kamada N. Establishment of a human acute myeloid leukemia cell line (Kasumi-1) with 8;21 chromosome translocation. Blood. 1991;77(9):2031-6.

19. Alessandri AJ, Knezevich SR, Mathers JA, Schultz KR, Sorensen PH. Absence of t(12;15) associated ETV6-NTRK3 fusion transcripts in pediatric acute leukemias. Medical and pediatric oncology. 2001;37(4):415-6.

20. Papaemmanuil E, Gerstung M, Bullinger L, Gaidzik VI, Paschka P, Roberts ND, et al. Genomic Classification and Prognosis in Acute Myeloid Leukemia. N Engl J Med. 2016;374(23):2209-21.

21. Roberts KG, Li Y, Payne-Turner D, Harvey RC, Yang YL, Pei D, et al. Targetable kinase-activating lesions in Ph-like acute lymphoblastic leukemia. N Engl J Med. 2014;371(11):1005-15.

22. Roberts KG, Gu Z, Payne-Turner D, McCastlain K, Harvey RC, Chen IM, et al. High Frequency and Poor Outcome of Philadelphia Chromosome-Like Acute Lymphoblastic Leukemia in Adults. Journal of clinical oncology : official journal of the American Society of Clinical Oncology. 2017;35(4):394-401.

23. Gu TL, Popova L, Reeves C, Nardone J, Macneill J, Rush J, et al. Phosphoproteomic analysis identifies the M0-91 cell line as a cellular model for the study of TEL-TRKC fusion-associated leukemia. Leukemia. 2007;21(3):563-6.

24. Chen S, Nagel S, Schneider B, Dai H, Geffers R, Kaufmann M, et al. A new ETV6-NTRK3 cell line model reveals MALAT1 as a novel therapeutic target - a short report. Cell Oncol (Dordr). 2018;41(1):93-101.

25. Forghieri F, Morselli M, Potenza L, Maccaferri M, Pedrazzi L, Paolini A, et al. Chronic eosinophilic leukaemia with ETV6-NTRK3 fusion transcript in an elderly patient affected with pancreatic carcinoma. Eur J Haematol. 2011;86(4):352-5.

Page 6/9 
26. Nardi V, Ku N, Frigault MJ, Dubuc AM, Tsai HK, Amrein PC, et al. Clinical response to larotrectinib in adult Philadelphia chromosome-like ALL with cryptic ETV6-NTRK3 rearrangement. Blood Adv. 2020;4(1):106-11.

27. Roberts KG, Janke LJ, Zhao Y, Seth A, Ma J, Finkelstein D, et al. ETV6-NTRK3 induces aggressive acute lymphoblastic leukemia highly sensitive to selective TRK inhibition. Blood. 2018;132(8):861-5.

28. Schewe DM, Lenk L, Vogiatzi F, Winterberg D, Rademacher AV, Buchmann S, et al. Larotrectinib in TRK fusion-positive pediatric B-cell acute lymphoblastic leukemia. Blood Adv. 2019;3(22):3499-502.

29. Matsuoka H, Murayama T, Koizumi T, Nishimura R, Kawaguchi R, Nakagawa T. Establishment of a human myeloid cell line with trisomy 8 derived from overt leukemia following myelodysplastic syndrome. Haematologica. 2005;90(7):981-2.

30. Jawhar M, Naumann N, Knut M, Score J, Ghazzawi M, Schneider B, et al. Cytogenetically cryptic ZMYM2-FLT3 and DIAPH1-PDGFRB gene fusions in myeloid neoplasms with eosinophilia. Leukemia. 2017;31(10):2271-3.

31. Setoyama M, Tojo A, Nagamura F, Asano S, Ishimae M, Eguchi M, et al. A unique translocation of the TEL gene in a case of acute myelogenous leukemia with inv(12)(p13q15). Blood. 1998;92(4):1454-5.

32. Sun Y, Kim SH, Zhou DC, Ding W, Paietta E, Guidez F, et al. Acute promyelocytic leukemia cell line AP-1060 established as a cytokine-dependent culture from a patient clinically resistant to all-trans retinoic acid and arsenic trioxide. Leukemia. 2004;18(7):1258-69.

33. Arce C, Cortes-Padilla D, Huntsman DG, Miller MA, Duennas-Gonzalez A, Alvarado A, et al. Secretory carcinoma of the breast containing the ETV6-NTRK3 fusion gene in a male: case report and review of the literature. World J Surg Oncol. 2005;3:35.

34. Pierson CR, Schober MS, Wallis T, Sarkar FH, Sorensen PH, Eble JN, et al. Mixed epithelial and stromal tumor of the kidney lacks the genetic alterations of cellular congenital mesoblastic nephroma. Hum Pathol. 2001;32(5):513-20.

35. Grimwade D, Hills RK, Moorman AV, Walker H, Chatters S, Goldstone AH, et al. Refinement of cytogenetic classification in acute myeloid leukemia: determination of prognostic significance of rare recurring chromosomal abnormalities among 5876 younger adult patients treated in the United Kingdom Medical Research Council trials. Blood. 2010;116(3):354-65.

36. Dohner H, Estey E, Grimwade D, Amadori S, Appelbaum FR, Buchner T, et al. Diagnosis and management of AML in adults: 2017 ELN recommendations from an international expert panel. Blood. 2017;129(4):424-47.

37. Coenen EA, Raimondi SC, Harbott J, Zimmermann M, Alonzo TA, Auvrignon A, et al. Prognostic significance of additional cytogenetic aberrations in 733 de novo pediatric 11q23/MLL-rearranged AML patients: results of an international study. Blood. 2011;117(26):7102-11.

38. Paschka P, Du J, Schlenk RF, Gaidzik VI, Bullinger L, Corbacioglu A, et al. Secondary genetic lesions in acute myeloid leukemia with inv(16) or t(16;16): a study of the German-Austrian AML Study Group (AMLSG). Blood. 2013;121(1):170-7.

39. Rubin BP, Chen CJ, Morgan TW, Xiao S, Grier HE, Kozakewich HP, et al. Congenital mesoblastic nephroma t(12;15) is associated with ETV6-NTRK3 gene fusion: cytogenetic and molecular relationship to congenital (infantile) fibrosarcoma. Am J Pathol. 1998;153(5):1451-8.

40. Chi HT, Ly BT, Kano Y, Tojo A, Watanabe T, Sato Y. ETV6-NTRK3 as a therapeutic target of small molecule inhibitor PKC412. Biochem Biophys Res Commun. 2012;429(1-2):87-92.

41. Eguchi M, Eguchi-Ishimae M, Green A, Enver T, Greaves M. Directing oncogenic fusion genes into stem cells via an SCL enhancer. Proc Natl Acad Sci U S A. 2005;102(4):1133-8.

42. Dubus P, Coindre JM, Groppi A, Jouan H, Ferrer J, Cohen C, et al. The detection of Tel-TrkC chimeric transcripts is more specific than TrkC immunoreactivity for the diagnosis of congenital fibrosarcoma. J Pathol. 2001;193(1):88-94.

43. Laetsch TW, DuBois SG, Mascarenhas L, Turpin B, Federman N, Albert CM, et al. Larotrectinib for paediatric solid tumours harbouring NTRK gene fusions: phase 1 results from a multicentre, open-label, phase 1/2 study. The Lancet Oncology. 2018;19(5):705-14.

44. Lange AM, Lo HW. Inhibiting TRK Proteins in Clinical Cancer Therapy. Cancers (Basel). 2018;10(4).

45. Drilon A, Siena S, Ou SI, Patel M, Ahn MJ, Lee J, et al. Safety and Antitumor Activity of the Multitargeted Pan-TRK, ROS1, and ALK Inhibitor Entrectinib: Combined Results from Two Phase I Trials (ALKA-372-001 and STARTRK-1). Cancer Discov. 2017;7(4):400-9.

46. Drilon A, Laetsch TW, Kummar S, DuBois SG, Lassen UN, Demetri GD, et al. Efficacy of Larotrectinib in TRK Fusion-Positive Cancers in Adults and Children. N Engl J Med. 2018;378(8):731-9.

47. Smith KM, Fagan PC, Pomari E, Germano G, Frasson C, Walsh C, et al. Antitumor Activity of Entrectinib, a Pan-TRK, ROS1, and ALK Inhibitor, in ETV6NTRK3-Positive Acute Myeloid Leukemia. Mol Cancer Ther. 2018;17(2):455-63.

\section{Figures}


A

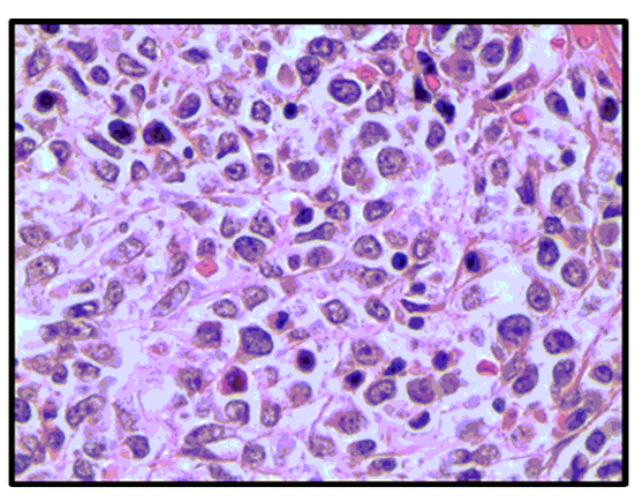

C

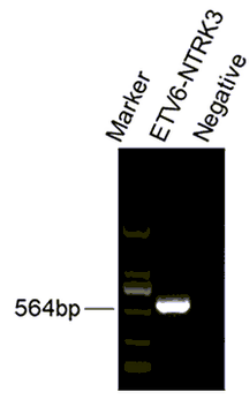

B

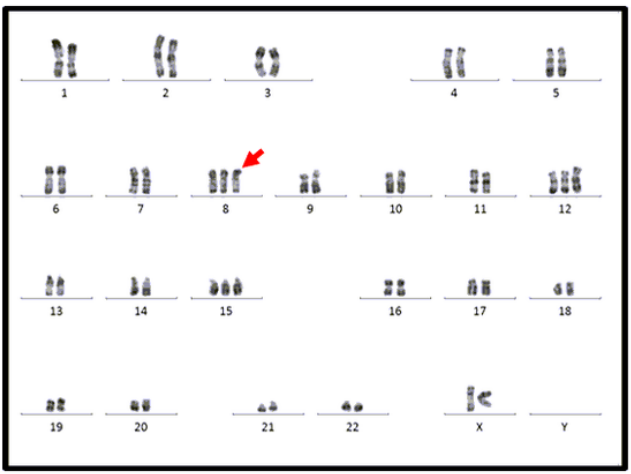

ETV6-exon5 $\downarrow$ NTRK3-exon15
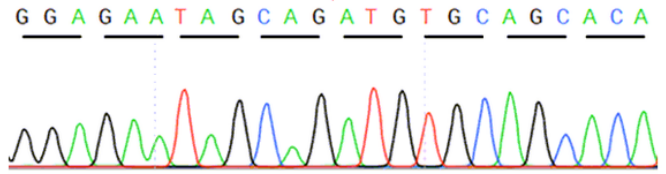

D

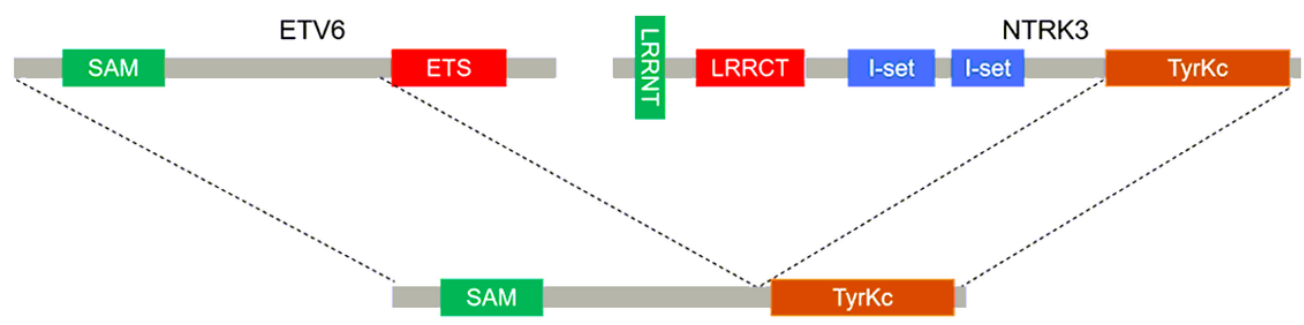

ETV6: exon5-exon15: NTRK3

Figure 1

Laboratory examinations of the AML patient carrying ETV6-NTRK3 fusion transcript. (A) The bone marrow biopsy specimen presented the diffuse and severe myelofibrosis in the context of hypercellular. (Wright-Giemsa). (B) R-banding analysis shows a karyotype of 49,XX,t(1;12)(q11;q11),inv(3) (p21q26), $+8,+12,+15,19 p+[10]$ in this patient at diagnosis. (C.D) Identification of the ETV6-NTRK3 fusion transcript. (C) RT-PCR for ETV6-NTRK3 fusion transcript with ETV6-F and NTRK3-R primers and the expected product size was $564 \mathrm{bp}$. Lanes B was the diagnostic sample. Lanes C was the negative control ddH2O. Lanes A was DNA marker. Sanger sequencing of the PCR product confirmed the fusion between exon 5 of the ETV 6 gene and exon 15 of the NTRK3 gene. (D) The structure diagram of the wildtype ETV6 gene, NTRK3 gene and ETV6-NTRK3 fusion transcript in this patient. 
A

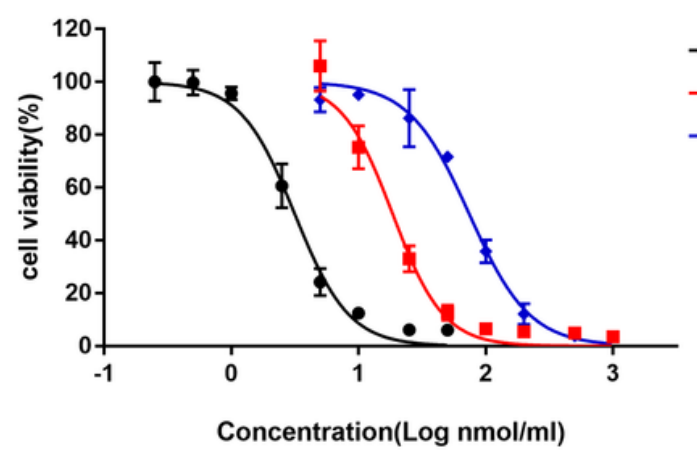

B

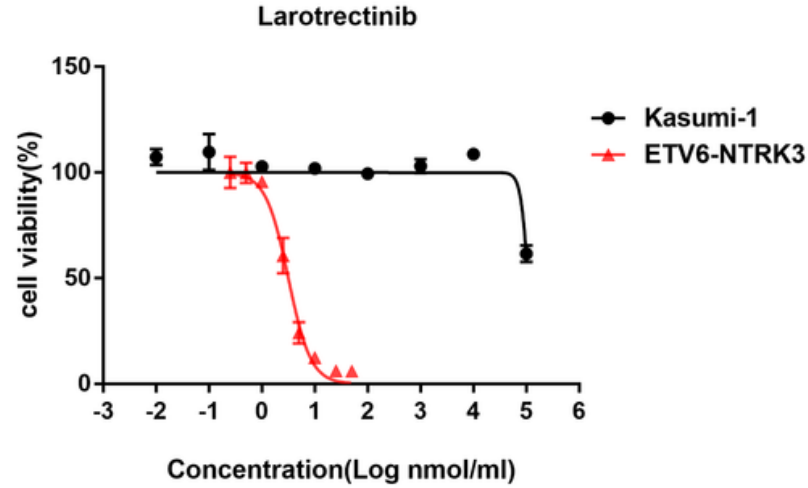

C

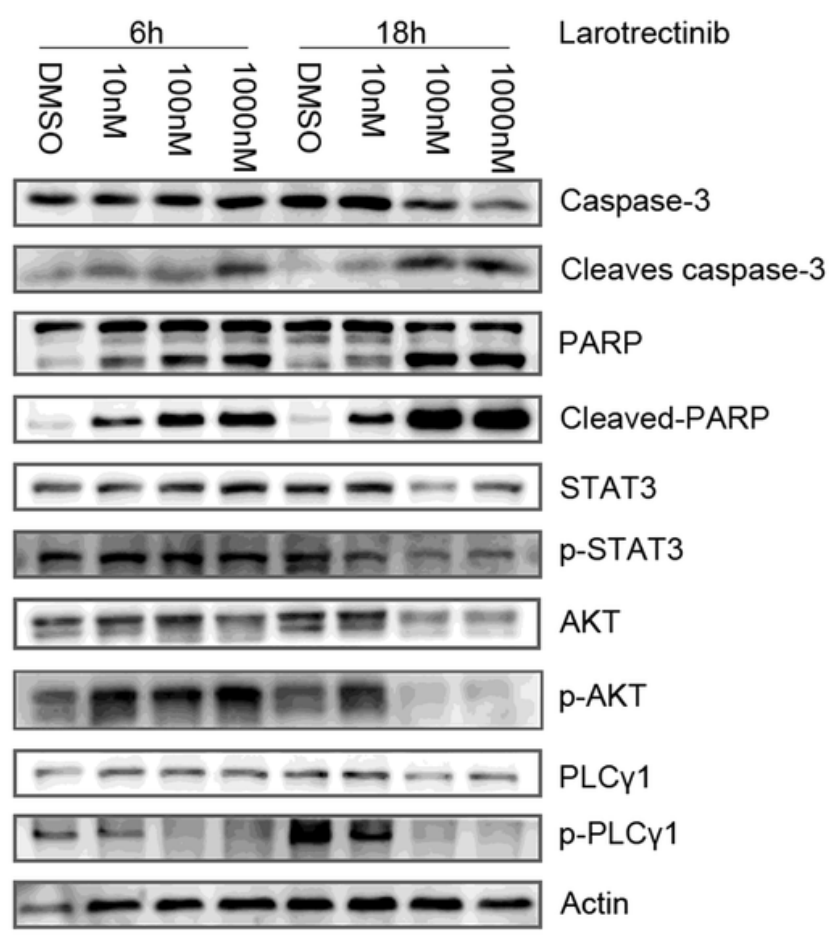

Figure 2

In vitro, ETV6-NTRK3-rearrangement patient derived primary bone marrow cells are sensitive to larotrectinib. (A) Primary bone marrow cells derived from the ETV6-NTRK3-positive patient at diagnosis were incubated in the medium of 1640 and 10\%FBS with serial dilutions of larotrectinib (black line), ponatinib (red line) and PKC412 (blue line). Cell viability was measured using the Cell Counting Kit-8 viability assay after 48-hour treatment. Compared to other kinase inhibitors (ponatinib, PKC412), larotrectinib was more potent and selective against the primary cells driven by the TRK-fusion alterations. IC50 values were determined using nonlinear regression (Prism 7.0). (B) The AML cell line Kasumi-1 was used as control for evaluating larotrectinib anti-proliferation effect as above. In contrast with the TRK-rearrangement primary cells, growth inhibition was observed in this non TRK-fusion cell line at a high concentration of larotrectinib $(105 \mathrm{nmol} / \mathrm{ml})$. (C) Whole cell lysates with increasing concentrations of larotrectinib treatment were harvested at 8 and 16 hours respectively. The inhibition of the phosphorylation of STAT3 (Y705), AKT (S473), and PLCY (Y783) and the cell death indicated by the elevated cleaved-PARP and Caspase-3 were both observed in a time- and does-dependent manner.

\section{Supplementary Files}

This is a list of supplementary files associated with this preprint. Click to download.

- Supplementarymaterials.doc 